Removal of the hypoplastic kidney produced a dramatic fall in blood pressure, and this remained low over the period of some months during which the patient was observed postoperatively.

REFERENCES

Higbee, D. R. (1944). J. Urol., 51, 466.

Lowsley, O. S. (1944). Year Book of Urology, p. 82, Chicago. Schwarz, H. (1924). Amer. J. Dis. Child., 27, 233.

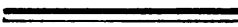

\section{ARSENICAL ENCEPHALOPATHY}

\section{AN UNUSUAL CASE OCCURRING IN THE TREATMENT OF CONGENITAL SYPHILIS}

\section{G. HIPPS, M.B., Ch.B. AND \\ R. GOLDBERG, M.B., Ch.B. Pinderfields E.M.S. Hospital}

The onset of acute cerebral symptoms occurring during, and attributable to, organic arsenical therapy is a well-recognized but rare clinical condition.

Arsenical encephalopathy was first described by Almkvist (1911), Fischer (1912), and Kannengiesser (1912). Its incidence is given by various authorities as follows. Only 8 cases are recorded from 800,000 intravenous injections of organic arsenicals given to the British Army in the 1914-18 war (Brit. Encyc. med. Pract., 1939). Glaser, Imerman, and Imerman (1935) estimate the mortality secondary to neurological involvement in standard arsenical therapy as 1 in 5,398. The incidence of arsenical encephalopathy is increased in the intensive treatment of syphilis; Stokes, Beerman, and Wammock (1943) estimate the mortality in the five-day treatment of syphilis as between 1 in 200/300. Rattner (1943) describes 481 cases of syphilis treated with $0.24 \mathrm{~g}$. mapharside by intravenous drip given daily for 5 days, in which 3 cases developed cerebral symptoms without fatal result. Craige and Sadusk (1944) report 74 cases of early syphilis in which no cerebral complications occurred following the same course of therapy. However, Goldstein, Stolman, and Goldfarb (1943) give the incidence of arsenical encephalopathy as $1.3 \%$ in intensive mapharside therapy.

We should like to present a case of arsenical encephalopathy occurring in a young adult with congenital syphilis, in whom we adopted the treatment suggested, and used with much success, by Ransome, Paterson, and Gupta (1945).

\section{Case Report}

The patient, a soldier with no overseas service, was admitted to this hospital on March 12,1946, for surgical treatment of a right inguinal hernia. His age was 20 , his general condition and physique were satisfactory. On examination he was found to have a left interstitial keratitis and iridocyclitis, and he gave a history of "inflammation of the eyes" for the past nine years. The Wassermann and Kahn reactions were both positive on two occasions in March, 1946. The hernia was treated successfully by radical surgery, and the following antisyphilitic therapy was adopted.

Local treatment consisted of subconjunctival injections of penicillin (500 units per ml.), penicillin drops, $2 \%$ atropine drops, and hot bathings. Systemic treatment was started on March 14 with 3-hourly intramuscular injections of penicillin-a total of 1.7 mega units being given. Arsenical therapy was begun on the $30 \mathrm{th}, 0.3 \mathrm{~g}$. neoarsphenamine being given twice weekly for 5 weeks, ending on May 10 A second similar course was started on July 5, the fifth injection of $0.3 \mathrm{~g}$. neoarsphenamine being given on the 19th. There had previously been no toxic reaction of any kind, and the eye lesions were slowly improving.

On July 20 he complained of malaise and frontal headache, which lasted until the next day, when he developed epileptiform convulsions. The aura (elicited on later questioning) consisted of "spots before the eyes." He fell on to his back, uttered a cry, and became unconscious. He then developed generalized spasticity with opisthotonos, and became deeply cyanosed. This stage lasted about a minute. It was followed by generalized clonic movements lasting 4 minutes and accompanied by severe tongue-biting and incontinence of urine and faeces. Consciousness was regained after 30 minutes, but he had no recollection of the attack except for the aura. Six similar convulsions occurred during the night, and between these he remained semicomatose and vomited prol isety. He was first seen by us while he was having these fits, and thereafte: was under our care.

On examination (July 21) the patient was comatose. All tendon reflexes were absent, and the abdominal reflexes could not be elicited. There was a bilateral extensor Babinski response, but no ankle or knee clonus. There was no neck rigidity or Kernig's sign. He had a conjugate deviation of the eyes to the right; the tight pupil reacted to light, but the left pupil was dilated under the therapeutic influence of atropine. The blood pressure was $135 / 90$. No physical signs were found in the other systems. The urine contained no albumin, sugar, or acetone bodies. There was no evidence of purpura, other skin lesions, or jaundice. On lumbar puncture the C.S.F. was under $90 \mathrm{~mm}$. pressure; there was no spinal block and the fluid was clear and colourless: 2 lymphocytes per c.mm., $170 \mathrm{mig}$. protein per $100 \mathrm{ml}$., $708 \mathrm{mg}$. chloride per $100 \mathrm{ml}$.; Lange curve, 0123555544; culture sterile; Wassermann reaction negative. The blood sugar was $117.6 \mathrm{mg}$. and the blood urea $47.1 \mathrm{mg}$. per $100 \mathrm{ml}$. The haemoglobin was $110 \%$, R.B.C. $6,000,000$, W.B.C. 11,600 (polymorphonuclears $71 \%$, lymphocytes $23 \%$, monocytes $6 \%$ ). No malarial parasites were found in the blood on thick and thin films.

A provisional diagnosis of arsenical encephalopathy was made, and treatment was adopted on the lines suggested by Ransome et al. (1945). They stress the prevention of cerebral oedema by postural nursing by keeping the patient's spine erect, repeated lumbar puncture, calcium thiosulphate, calcium gluconate, vitamin $C$, and adequate fluid intake. Our patient was sat up in a vertical position, given $1 \mathrm{ml}$. of adrenaline $(1$ in 1,000$)$ and 1 pint $(568 \mathrm{ml}$.) of $20 \%$ glucose by slow intravenous drip in an attempt to prevent cerebral oedema. Calcium thiosulphate $0.6 \mathrm{~g}$., $10 \mathrm{ml}$. of $10 \%$ calcium gluconate, and $500 \mathrm{mg}$. of vitamin $\mathrm{C}$ were each given intravenously at 6-hourly intervals for the first day and then daily. Fluids were given ad lib. by an intranasal Ryle's tube.

The next day (July 22) the coma gradually deepened and he became cyanosed. There were no signs of congestive heart failure, and venesection was not indicated. Continuous nasal oxygen was given. On the 23rd he was sweating profusely and in deep coma. There were slight neck rigidity and a doubtful Kernig's sign on the right. He had marked twitching of the right arm and leg, and the extensor responses were still present. The temperature had risen to $104^{\circ} \mathrm{F}$. $\left(40^{\circ} \mathrm{C}\right.$.). One pint $(568 \mathrm{ml}$.) of isotonic glucose-saline was given by slow intravenous drip to combat slight dehydration. Lumbar puncture was repeated. The C.S.F. was clear and colourless, and the pressure was $90 \mathrm{~mm}$. There were 7 cells per c.mm. (equal numbers of polymorphs and lymphocytes), and the protein was 110 mg. per $100 \mathrm{ml}$.; Lange curve, 0123455433 ; chlorides, $727.5 \mathrm{mg}$. per $100 \mathrm{ml}$.; culture sterile.

On the 24th the coma was much deeper, the cyanosis more marked (despite oxygen therapy), and he was breathing stertorously. The pupils were fixed to light, and there were slight neck rigidity and a bilateral slight Kernig's sign. All deep tendon reflexes were absent, and there was still a bilateral Babinski response. The temperature had risen to $105^{\circ} \mathrm{F}$. $\left(40.6^{\circ} \mathrm{C}\right.$.), where it remained until his death early on the 25 th.

Necropsy was performed by Prof. P. L. Sutherland, who reported that the cerebral convolutions were slightly flattened and the superficial cerebral vessels congested. The ventricles of the brain contained a little blood-stained fluid and the choroid plexuses were deeply congested. Numerous petechial haemorrhages were found on the visceral pleura of both lungs, and there were signs of a terminal bronchopneumonia. The liver and kidneys were normal in appearance and also histologically. Histological examination showed slight thickening of the pia mater. The vessels of the basal ganglia were unduly prominent and some appeared to be thrombosed. There was slight focal demyelination, but no other evidence of cerebral lesions. Obermiller (1913) and Stühmer (1919) state that there may be no pathological changes in arsenical encephalopathy other than cerebral congestion and oedema. The characteristic lesion, however, in this condition is multiple plugged capillaries with petechial haemorrhages and surrounding necrosis and demyelination (Russell, 1937; Strauss and Globus, 1930; Alpers, 1928).

\section{Differential Diagnosis}

We consider this case to be one of arsenical encephalopathy, for the following reasons. There was no personal or family history of epilepsy; there was no previous evidence of cerebral syphilis, and it is very unlikely that he would develop the first signs of this after starting treatment with penicillin and arsenic and in the presence of a negative C.S.F. Wassermann reaction. The blood pressure and blood urea were normal and there was no albuminuria, thus eliminating hypertensive encephalopathy and uraemia. The blood sugar was normal, and there was no glycosuria or acetonuria, ruling out diabetic coma or spontaneous hypoglycaemia. The patient did not have any other 
drugs apart from arsenic and penicillin. There was no history of malaria, and the blood films proved negative for plasmodia.

\section{Discussion}

There are several interesting and unusual features about this case. (1) Very few cases of arsenical encephalopathy in congenital syphilis can be found in the literature. (2) He was given a short course of systemic penicillin prior to arsenical therapy. (3) $\mathrm{He}$ had 15 injections of $0.3 \mathrm{~g}$. neoarsphenamine (i.e., a total dosage of 4.5 g.) before the onset of cerebral symptoms. According to Glaser et al. (1935) only one case is recorded in the literature in which 15 injections had been given before the onset of encephalopathy, and only $6 \%$ of all recorded cases had received a total dose of more than $2 \mathrm{~g}$. of organic arsenicals. In over $75 \%$ of recorded cases the encephalopathy occurred before the fifth injection. Our case supports the now overwhelming evidence that arsenical encephalopathy is not a Jarisch-Herxhe:mer reaction but due to a hypersensitivity to organic arsenicals. (4) Death usually occurs within 48 to 72 hours of the onset of symptoms, whereas our patient survived over four days.

The treatment adopted was that advocated by Ransome et al., which they used with success in all of their 5 cases, in a condition which has an average mortality of $76 \%$ (Glaser et al., 1935 ; Kinnear Wilson, 1940). Our patient, however, did not respond, and died in coma on the fifth day of the disease.

\section{Summary}

A case of arsenical encephalopathy is recorded. The patient was a congenital syphilitic with interstitial keratitis and iridocyclitis, and was being treated with penicillin and neoarsphenamine. Treatment on the postural basis of Ransome et al. was instituted, but did not stcceed in saving the patient's life.

We wish to express our gratitude to $\mathrm{Dr}$. H. H. Moll, consultant physician; Mr. George Black, consultant ophthalmologist; Prof P. L. Sutherland, consultant pathologist; to our colleagues for their co-operation in the investigations, and to Dr. R. A. Russell Taylor for permission to pubiish this case.

\section{REFERENCES}

Almkvist, J. (1911). Münch. med. Wschr., 58, 1809.

Alpers, B. J. (1928). Arch. Neuro. Psychiat., Chicago, 20, 497

Brit Encyc med Pract. (1939) i1 592 ,

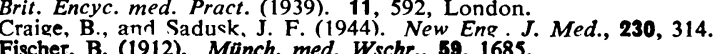

Glaser. M. A., Imerman, C. P., and Imerman, S. W. (1935). Amer. J. med. Sci. 189,64 .

Goldstein. D. H.. Stolman. A., and Goldfarb. A. E. (1943). Science, 98, 245.

Kannengiesser (1912). Münch. med. Wschr., B9, 1225.

Ransome, G. A.. Paterson, J. C. S., and Gupta, L. M. (1945). British Medical Journal, $1,659$.

Rattner, H. (1943). J. Amer. med. Ass., 122, 986.

Russell, D. S. (1937). J. Path. Bact., 45, 357 .

Stokes, J. H., Beerman, H., and Wammock, V. S. (1943). Amer. J. med. Sci. 206, 521 .

Strauss, I., and Globus, J. H. (1930). J. nerv. ment. Dis., 72, 557.

Stahmer, A. (1919). Manch. med. Wschr., 66, 96.

Wilson, S. A. Kinnear (1940), Neurology, London.

\section{Medical Memoranda}

\section{Compound Gridiron Approach to the Appendix in Difficult Cases}

Sooner or later every surgeon encounters the long retrocaecal appendix which is firmly fixed the whole way from its base in the right iliac fossa to its apex in the region of the hepatic flexure of the colon, and where normal incisions give inadequate access. I have found the following technique invaluable in such cases.

The usual McBurney incision is used in the first place, and when the above condition is revealed the subsequent procedure is as follows: (1) extend the skin incision up towards the loin ; (2) split the external oblique muscle fibres to the limit of the incision; (3) split the internal oblique and transversalis muscles in the line of their fibres at the upper end of the wound; and (4) open the peritoneum in the above situation. The wound thus consists of the extended incision through the skin and external oblique muscle in the line of its fibres, and the double split in the internal oblique and transversalis muscles in the line of their fibres at the upper and lower extremities of the wound, with a peritoneal opening deep to each of the latter. The distal part of the appendix is then easily freed via the upper opening and the proximal part through the lower; the whole organ can then be delivered safely through the lower opening. The peritoneum and muscles are subsequently closed in the usual manner.

This approach has the following advantages: (1) the appendix is adequately exposed; (2) it causes the minimum of trauma (3) the added access is easy and avoids cutting of muscle ; (4) healing is good and the scar is sound; and (5) the area can be drained, if necessary, via the lower grid without fear of breakdown of the whole wound.

Oxford.

\section{J. HUGHES, F.R.C.S.}

\section{A Rare Cause of Foetal Death}

The following case of intrauterine death may be of interest owing to the rarity of the cause.

\section{CASE History}

A primipara aged 24 was admitted to hospital at 4.15 p.m. on Feb. 25, 1946, with a history of ruptured membranes at 9.30 the previous evening. The expected date of delivery was March 11. The fundus was 38 weeks, with the vertex presenting (left occipitoanterior). The head was high and freely ballotable. The foetal heart was distinctly heard and was quite regular. There was no oedema or albuminuria. The blood pressure was $120 / 80$, the temperature $97^{\circ} \mathrm{F}$. $\left(36.1^{\circ} \mathrm{C}\right.$ ), and the pulse 84 . She was not having pains, nor did she have pains before or after the rupture of the membranes. She was a booked case, and had attended the routine antenatal clinics regularly. Her external measurements were: interspinous $9 \frac{1}{2}$ in. $\left(24 \mathrm{~cm}\right.$.), intercristal $10 \frac{1}{2}$ in. $(26.5 \mathrm{~cm}$.), external conjugate $7 \frac{1}{2}$ in. $(19 \mathrm{~cm}$.). Owing to the non-fixation of the head she had been put down for a trial of labour.

Progress.- On the night of Feb. 25 the patient was rather restless and complained of not being able to sleep, so she was given phenobarbitone, $3 \mathrm{gr}$. $(0.2 \mathrm{~g}$.). The liquor was draining freely. She slept well through the night. Next morning she was given $1 \frac{1}{2} \mathrm{oz}$ $(42 \mathrm{ml}$ ) of castor oil, and a tight binder and pads were applied to the abdomen. Throughout the day the patient remained comfortable and did not complain of pains. Abdominal examination in the afternoon showed the head to be in the same position as on admission. At $8.15 \mathrm{p} . \mathrm{m}$. she suddenly had a bright-red loss and passed some large clots, and pains began. Bleeding continued with each pain. The foetal heart was auscultated and was still quite audible and regular. Examination was made per vaginam; the os was two-fingers dilated, the head was reached, and no placenta was palpated. A tentative diagnosis of high lateral placenta praevia was made. At $10.40 \mathrm{p} . \mathrm{m}$. the foetal heart became difficult to hear. The baby's condition was explained to the patient and she was told that even with a caesarean section the chances of delivering a live infant were very problematical. She and the relatives decided for an immediate operation in the baby's interests. The mother's condition was very good; pulse strong and regular, rate 90. A lower-segment caesarean section was performed under spinal anaesthesia. At operation the lower segment was thin, and the line of demarcation between it and the upper segment was well marked. A stillborn male infant was extracted. The placenta was situated in the fundus uteri; it was removed, together with the membranes, without difficulty.

Findings.-After the operation the baby and placenta were examined. The infant was $7 \mathrm{lb} .12 \mathrm{oz} .(3.5 \mathrm{~kg}$.) in weight, 20 in. $(50 \mathrm{~cm}$.) long, and appeared to be normal. Attention was next directed to the afterbirth, and it was then seen that the umbilical cord was inserted outside the placental margin, and numerous large vessels were running beneath the amnion, entering separately into the placental margin-that is, a velamentous insertion of the cord. Furthermore, it was discovered that these vessels were lying between that part of the membranes situated in the lower uterine segment. The rupture of the membranes had taken place along the line of one of these vessels, and about 3 in. $(7.5 \mathrm{~cm}$.) from the placental margin a small tear was found in the wall through which blood was still exuding. The cause of the foetal death was now obvious.

It would appear that in cases of ante-partum haemorrhage with no toxaemic signs or demonstrable placenta praevia, even this rare anomaly should be borne in mind.

I am indebted to Dr. C. B. Crane, M.O.H. for York, for permission to publish this note.

P. P. KIRWAN, L.R.C.P.\&S.I., Resident Medical Officer. City 